\title{
Iniquidades Sociais no contexto da Atenção Primária à Saúde
}

\author{
Social Inequalities in the Primary Health Care context \\ Iniquidades Sociales en el contexto de Atención Primaria a Salud \\ Armando Henrique Norman ${ }^{1 *}$
}

A edição $\mathrm{n}^{\circ} 25$ da RBMFC traz temas interessantes para os profissionais da APS/ESF, a começar pela experiência em uma unidade de saúde da Espanha que implementou o programa Mentoring para a capacitação de profissionais médicos e enfermeiros na realização de pequenas cirurgias e/ou procedimentos. Esse artigo explora o potencial instalado nos serviços de saúde para multiplicação de conhecimentos e habilidades entre pares, visando atender a carteira de serviços e melhorar tanto a resolutividade do profissional (e consequente autoestima) como a satisfação dos usuários do sistema de saúde. Já na seçáo Ensaios, o artigo Hiperplasia Prostática Benigna e PSA: o efeito dominó discute um tema polêmico, visto que a recomendaçáo atual do USPSTF é contrária ao rastreamento do câncer de próstata ${ }^{1}$. As diversas diretrizes sobre o PSA e HPB variam em suas recomendaçôes, desde a não utilizaçáo até o uso rotineiro da dosagem do PSA. Porém, o autor traz à tona a necessidade de não se inserir como rotina o teste do PSA no cuidado do paciente com sintomas sugestivos de HPB, pois esses sintomas não aumentam a probabilidade pré-teste para câncer de próstata. Desse modo, esse tema constitui um caso exemplar para a prática da prevenção quaternária ${ }^{2}$. Segundo Gérvas ${ }^{3}$ nenhum processo de diagnóstico/tratamento está isento de dano e se os médicos usam-no sem uma sólida evidência científica de seu benefício, estâo expondo os pacientes a riscos, ao invés de oferecerem benefícios.

Vinculados à questão da formação e prática em APS, destacam-se dois artigos: na seçáo Perspectiva o artigo Oficina acadêmica: bases curriculares e Medicina de Família e Comunidade, construído a partir de um debate no IV Congresso Mineiro de Medicina de Família e Comunidade, faz uma discussão sobre a graduação em medicina e a necessidade de incorporaçáo dos temas relacionados à MFC; e na seção Relato de Casos um artigo sobre a formação multiprofissional em saúde da família e a discussão sobre os desafios de estimular a reativação de um Conselho Local de Saúde (CLS) em face às dificuldades e a legitimação do 'status quo'. Os CLSs e o engajamento com as questóes da comunidade sáo importantes na formação dos profissionais de saúde, pois contextualizam sua práxis e promovem o vínculo entre profissionais e moradores assistidos pela Unidade de Saúde da Família (USF). Assim, esse espaço político poderia ser melhor explorado nos processos de formação, dada sua relevância para a inclusão social e fortalecimento do SUS.

\footnotetext{
${ }^{1}$ Mestre em Antropologia Médica pela University of Durham, Reino Unido, Especialista em MFC. editor.rbmfc@sbmfc.org.br

*Autor correspondente.
} 
Em sua grande maioria, os profissionais de saúde da APS trabalham em realidades que mesclam dois tipos de situação, fruto da exclusão social: a pobreza e a iniquidade. A primeira é bem conhecida, por seus efeitos deletérios sobre a saúde e inclui: falta de saneamento básico, condiçôes de moradia inadequadas, desemprego, etc. A segunda é mais sutil, pois é difícil 'mensurar' e/ou documentar a via fisiopatológica dos efeitos da iniquidade social sobre a saúde. Entretanto, o estudo de coorte Whitehall I, construído para ser o 'Framingham Britânico', mostrou que os marcadores tradicionais (hipertensão, colesterol, diabetes, obesidade, etc) explicavam apenas $1 / 3$ da diferença de morbimortalidade entre os servidores públicos situados no topo do organograma administrativo e aqueles que ocupavam níveis mais baixos da mesma instituição pública ${ }^{4}$. Por exemplo, o risco relativo de mortalidade cardiovascular era de 2.2 para auxiliares de escritório, quando comparado aos administrativos sênior. A questáo é: porque haveria um gradiente social de morbimortalidade, uma vez que todos no estudo viviam acima da linha de pobreza, dentro de um país que, se comparado com o Brasil, apresenta uma forte política de bem estar social? Para responder a essa pergunta fez-se o estudo coorte Whitehall II, conduzido por Michael Marmot, que confirmou que fatores psicossociais estariam na base desse gradiente social em saúde. O Whitehall II demonstrou que o baixo controle sobre o processo de trabalho é um preditor de Doença Arterial Coronariana (DAC), independentemente do status social, e que este era responsável por metade do gradiente social para doença cardiovascular ${ }^{5}$. Para Marmot, três principais fatores influenciam o gradiente social em saúde: o senso subjetivo de controle sobre suas circunstâncias de vida (laboral e familiar), o grau de coesão social e a rede de suporte (família, amigos e/ou colegas de trabalho). Segundo ele, quanto maior a coesão social melhores os desfechos em saúde, tanto para ricos como para pobres. Nas sociedades menos desiguais, o senso de pertencer, de coesáo social e de segurança são maiores e por isso, os efeitos benéficos sobre a saúde ocorrem também para os mais ricos nestas sociedades ${ }^{6}$. Por exemplo, na Inglaterra/País de Gales, a mortalidade infantil é maior para todos os estratos sociais, quando comparada com a Suécia. Ou seja, as crianças inglesas, nascida de famílias ricas, morrem mais do que as crianças suecas, também nascidas de pais ricos. Do mesmo modo, a mortalidade infantil das crianças nascidas de mães solteiras inglesas é o dobro $(-14 / 1000)$ quando comparada as crianças nascidas de mães solteiras suecas $(-7 / 1000)^{7}$. Esses dados ilustram que o efeito da igualdade social é benéfico para todos os segmentos da estrutura social.

Três artigos que compóem a presente edição perpassam as reflexôes acima, pois tratam de certo modo, de questóes relativas às desigualdades sociais no Brasil. $\mathrm{O}$ artigo 'Consumo de bebidas alcoólicas entre trabalhadores de uma Unidade de Saúde da Familia em Vitória, Espirito Santo, Brasil' explora o padrão de consumo de bebidas alcoólicas pelos trabalhadores de uma USF, que em certa medida aponta para a existência de um gradiente social de consumo de bebidas alcoólicas. Já o artigo que trata do surto de dengue ocorrido em Aracaju em 2008, revela um problema importante de saúde pública e a necessidade de uma vigilância em saúde capaz de, a partir da análise dos dados epidemiológicos, elaborar estratégias para seu efetivo controle. Entretanto, os números revelam que os mais acometidos são aqueles desfavorecidos socioeconomicamente. Por fim, o artigo 'Não aceitação da gravidez e o desenvolvimento da criança aos quatro anos de idade no bairro Vila Jardim, Porto Alegre, Rio Grande do Sul, Brasil' faz uma associaçáo entre 'gravidez não desejada' e problemas para o desenvolvimento da criança aos quatro anos de idade. Mesmo dentro de um contexto político-social anti-aborto, segundo a OMS, no Brasil a taxa de aborto chega a 31\%. Nesse sentido, as autoras alertam os profissionais de saúde para que estejam atentos durante o pré-natal (abordando o significado da gravidez para a gestante e/ou casal nas famílias das classes sociais média-baixa e baixa), e adotem medidas preventivas que possam minimizar tais efeitos adversos para as crianças. Essas questôes que abordam fatores psicossociais são importantes, visto que, os profissionais de saúde da APS se caracterizam por buscarem estratégias que transcendam o modelo biomédico, reducionista e centrado em patologias. Situando cada caso individualmente em seu contexto 
familiar e comunitário é que profissionais da APS/ESF podem fazer a diferença ao cuidarem de seus pacientes.

Essa edição também presta homenagem ao Dr. Luiz Felipe Cunha Mattos que nos deixou precocemente, depois de anos de serviços prestados a sua gente e a especialidade. Na seção Memória, escrita pelo Dr. José Mauro C. Lopes, é retratada um pouco da doação que o Dr. Luiz Felipe fez a sociedade, nas diversas instâncias em que atuou enquanto MFC. Para Needelman ${ }^{8}$ o que define a natureza humana é a capacidade "de doação", pois tudo o que recebemos é para esse fim, ou seja, 'somos feitos para servir's . Nesse sentido, a vida do Dr. Luiz Felipe fez a diferença para a MFC no Brasil.

Nessa última edição de 2012, gostaria de agradecer: a diretoria da SBMFC na figura do Dr. Nulvio Lermen Junior; aos autores e a todos os avaliadores que tem voluntariamente colaborado, 'doando' seu tempo e seu trabalho, assegurando assim, a qualidade dos conteúdos publicados pela RBMFC. Também meu agradecimento ao secretariado da revista, David Milhomens e Josane Norman e, em especial, a equipe da Editora Cubo pela dedicaçáo e parceria no fechamento desta última edição de 2012.

Termino esse editorial desejando a todos um ano de 2013 repleto de realizaçóes e que a RBMFC possa seguir cumprindo seu papel social e científico para a sociedade.

\section{Referências}

1. United State Preventive Services Task Force. Screening for prostate cancer. U.S. Preventive Services Task Force Recommendation statement; 2012. [acesso em 16 dec. 2012]. Disponível em: http://www. uspreventiveservicestaskforce.org/prostatecancerscreening.htm

2. Norman $A H$, Tesser $C D$. Prevenção quaternária na atenção primária à saúde: uma necessidade do Sistema Único de Saúde. Cad Saúde Pública. 2009; 25(9): 2012-20. http://dx.doi.org/10.1590/S0102-311X2009000900015

3. Gérvas J. Screening for serious illness: limits to the power of medicine. Eur J Gen Pract. 2002; (8). Editorial.

4. Marmot M, Brunner E. Cohort Profile: the Whitehall II study. Int J Epidemiol. 2005; 34(2): 251-6. Available at: http://www.ncbi.nlm.nih.gov/pubmed/15576467 [acesso em 7 nov. 2012]. http://dx.doi.org/10.1093/ije/dyh372

5. Marmot M, Wilkinson RG. Psychosocial between income and health: a response to Lynch et al. BMJ 2001; 322: 1233-36. http://dx.doi.org/10.1136/bmj.322.7296.1233

6. Helman CG. Culture, Health and IIness. 5th ed. London: Hodder Arnold; 2007. n. 1, p. 6-7.

7. Wilkinson R, Pickett K. The Spirit Level: Why Equality is Better for Everyone. London: Penguin; 2010. n. 13, p. $178-9$

8. Needleman J. The Way of the Physician. New York: Penguin Books; 1992. First published in 1985 and reprinted in 1992. n. 2, p. 11. 
